\title{
Can biomarkers of biological age be used to assess cumulative lifetime experience?
}

\author{
M Bateson* and C Poirier
}

\begin{abstract}
Institute of Neuroscience and Centre for Behaviour and Evolution, Newcastle University, Newcastle-upon-Tyne, UK
\end{abstract}
* Contact for correspondence and requests for reprints: Melissa.Bateson@ncl.ac.uk

\begin{abstract}
Objective methods for assessing the cumulative lifetime experience of non-human animals would be valuable. We develop the hypothesis that biological age is a common currency that integrates the overall quality of an animal's lifetime experience across a range of types of exposure. Ageing is the result of the accumulation of somatic damage, and its rate is determined by the balance between experiences that cause damage and experiences that mitigate damage or promote repair. Negative affective states are associated with somatic damage via both direct causal and indirect pathways. Based on these premises, we predict that individuals that are biologically old for their chronological age will, on average, have experienced worse lives than individuals that are biologically younger, both in terms of their overall health and affective experience. Biological age is, thus, an attractive measure of cumulative experience because it requires no subjective decisions either about how a given exposure impacts an animal, or about how different dimensions of welfare should be weighted in an overall assessment. Biological age can be measured objectively using biomarkers. We argue that two biomarkers, namely leukocyte telomere length and hippocampal volume, are valid biomarkers of cumulative experience in humans, with potential for use in non-human vertebrates. We discuss how these biomarkers could be used to assess cumulative experience in animals, highlighting some of the limitations. We conclude that biomarkers of biological age offer a viable objective solution to the assessment of cumulative experience and their application in an animal welfare context deserves further exploration.
\end{abstract}

Keywords: animal welfare, biological age, exposome, hippocampus, lifetime experience, telomere length

\section{Introduction}

In recent years, there has been an increased emphasis in animal welfare on optimising the cumulative lifetime experience of both laboratory and farm animals. This focus is driven by the recognition that while single experiences can be acutely positive or negative, what matters more from a welfare perspective is the lasting cumulative impact of these experiences; it is the overall balance between positive and negative experiences over an animal's lifetime that determines its average quality of life. A focus on cumulative experience is present both in recommendations for improving the welfare of farm animals, which have introduced the concepts of 'a life worth living' and 'a good life' (Farm Animal Welfare Council [FAWC] 2009), and also in legislation governing the use of animals in scientific research, which has introduced the related concepts of 'cumulative severity' and 'cumulative suffering' (European Parliament \& European Council 2010; Honess \& Wolfensohn 2010; Pickard 2013). Current European legislation regulating the use of animals in research now requires both prospective and retrospective assessment of the cumulative effects of research on animal welfare (European Parliament \& European Council 2010).
What exactly is cumulative experience? In the laboratory animal literature, cumulative experience is used to refer to the sum of all impacts on the health and well-being of an animal over its lifetime from conception to death or the present time (Pickard 2013). An identical definition could be adopted for farm, zoo and companion animals. For a laboratory rat (Rattus norvegicus), impacts contributing to cumulative experience might arise from maternal health, litter size, age of weaning, cage type, number and type of scientific procedures and method of euthanasia. For a broiler chicken (Gallus gallus domesticus), impacts might arise from flock size, husbandry, feather-pecking, pathogen load, lameness, transport and slaughter. In the Pickard report definition, we interpret well-being to mean affective state, and more specifically the long-term states that are influenced by an animal's history of acute emotional experiences (Mendl et al 2010; Nettle \& Bateson 2012). Thus, both health and affective state contribute to cumulative experience, making the definition similar to the concept of animal welfare advocated by Dawkins (2006, 2017). Some experiences will have negative impacts on health and well-being, whereas others will have positive impacts; some impacts will be long-lasting, whereas others will be short-lived. Some husbandry decisions may 
even have different impacts in the short and long term. For example, rewarding rhesus macaques (Macaca mulatta) with sweets may have a positive impact on their affective state in the short-term, but result in negative impacts on health and affective state arising from obesity and tooth decay in the longer term. The problem currently facing animal welfare scientists is how cumulative experience can be assessed in non-human animals.

A variety of methods have been suggested for assessing cumulative experience (for a review, see Pickard 2013). Measuring single welfare indicators has the advantage of being objective, but all current approaches suffer from limitations. Single measures, such as bodyweight and cortisol levels, have the advantage of being practical to measure, but are insensitive and non-specific making them hard to interpret (Ralph \& Tilbrook 2016). Single behavioural measures, such as the presence of stereotypies, are also relatively simple to measure and may relate better to some aspects of past exposures (eg Gottlieb et al 2013; Greco et al 2016), but can also be hard to interpret and need to be validated for each species (Mason \& Latham 2004; Poirier \& Bateson 2017). Perhaps the most promising single behavioural measures developed, thus far, are so-called 'cognitive biases', that are argued to provide an integrative measure of affective state (Paul et al 2005; Mendl et al 2009, 2010). A major advantage of cognitive bias measures is that they are considered specifically sensitive to the valence of affective state and their interpretation is likely to generalise across species. However, the behavioural tasks required to measure cognitive biases still need to be developed and validated within each species and typically require extensive training of the animals, making them impractical for applied welfare assessment in their current form.

Due to the difficulties outlined above, measures that integrate several simple welfare indicators are currently the favoured method for practical assessments of cumulative experience. 'Clinical impression', cited in UK law relating to laboratory animals (UK Government 2012), involves a veterinary examination and consideration of all potentially relevant information available. However, this approach is currently poorly specified and lacks standardisation. It is also prone to using subjective or anthropomorphic criteria. To address these criticisms, practical methods have been developed for integrating multiple welfare indicators that are standardised and transparent. These include the Extended Welfare Assessment Grid for laboratory animals (Honess \& Wolfensohn 2010) and the Welfare Quality ${ }^{\circledR}$ scheme for farm animals (eg Welfare Quality® 2009). However, a major criticism of all these approaches is that they rely critically on two sets of untested assumptions. The first set of assumptions concerns how specific exposures impact an animal's cumulative experience, and the second set concerns how different dimensions of welfare (eg physical health versus affective state) are weighted in the overall assessment of cumulative experience.

The crux of the problem is therefore that there is currently no objectively measurable common currency for measuring cumulative experience that is sensitive to the impact of the various exposures that an animal has over its lifetime. The Pickard report on the assessment of cumulative severity in non-human primates used in neuroscience research reached the depressing conclusion that, "There is no mathematical way of integrating all positive and negative events in an animal's life" (Pickard 2013). Our aim in this essay is to ask whether measuring biomarkers of biological age might provide a novel solution to this problem that goes some way towards addressing the criticisms that we have made of existing approaches.

We start by introducing two central concepts that we borrow from human epidemiology and biomedical science: the exposome and biological age. We highlight the importance of distinguishing between the totality of the variables to which an animal is exposed over its lifetime — its exposome - and the magnitude and duration of any impacts that these exposures have on the individual animal's experience. We develop the hypothesis that biological age is a common currency, measured in units of time, that integrates the somatic impact (both damaging and restorative) of an animal's exposome, taking into account variation in stress resilience. We argue that exposures that increase biological age usually also have a negative impact on long-term affective state, whereas those that either slow ageing or decrease biological age usually also have a positive impact on long-term affective state. Thus, in addition to being associated with health, biological age is likely to be associated with the cumulative affective impact of experience. It follows that cumulative experience can be assessed via the difference between an animal's biological and chronological ages. We introduce two biomarkers of biological age that we argue have promise for assessing cumulative experience, namely measures of telomere length and hippocampal volume. We end by describing how biomarkers could be used to assess cumulative experience and discuss some limitations of the biomarker approach.

\section{Cumulative experience and the exposome}

The 'exposome' is a concept developed in the human epidemiology literature that describes every exposure to which an individual is subjected from conception to death (Wild 2005, 2012). The aim of the exposome is to provide a neutral description of the totality of an individual's nongenetic exposure that can then be used to identify those specific exposures associated with well-being, health and disease. According to Wild's (2012) original conception, the exposome integrates exposures in three domains that reflect the different types of information about an individual that are available to epidemiologists: first, the general external social and ecological context in which the individual lives, second, the specific external events or agents to which the individual is exposed and third, the internal environment of the body. General external exposures are likely to determine specific external exposures, and the internal environment of the body will, at least partially, be a response to the external environment of the animal. Furthermore, internal state will sometimes, via changes in behaviour, bring about changes in external exposures. External exposures can be thought of as operating at the organismal level, whereas internal exposures are at the cellular level (for a use of this distinction, see Bateson 2016). In Figure 1, we have adapted the concept of the exposome for a laboratory rat. 
This formulation of the exposome highlights three points that are relevant to the concept of cumulative experience. First, not all external exposures will necessarily cause changes in internal exposures. This is important because an external exposure can only cause a lasting somatic impact if it produces some change in internal exposure. For example, exposure to environmental ultrasound causes depressive symptoms in laboratory rats and mice (Mus musculus) (Morozova et al 2016), but is undetectable to adult humans. In a similar vein, exposure to the flicker of low frequency, fluorescent lighting raises corticosterone levels in European starlings (Sturnus vulgaris) (Smith et al 2005), but is undetectable to humans. Thus, some aspects of the exposome may be completely irrelevant to cumulative experience in some species. The examples given here highlight the dangers of anthropomorphism in deciding which exposures might be relevant to the experience of non-human animals.

Second, not all internal exposures will necessarily produce lasting somatic impacts. Exposures could involve temporary changes in the internal exposome that leave no lasting somatic record necessary for effects to accumulate over time. For example, it is possible that infrequent exposure to minor acute stress, while producing a temporary spike in glucocorticoid stress hormones lasting an hour or two, produces no permanent change in either HPA-axis function or the brain.

Third, even if a given external exposure does produce a lasting impact on somatic state, the magnitude and duration of this impact may not be constant, either between, or within individuals. There are multiple reasons why there is variation in how individuals experience their exposome. Stable individual differences in stress-sensitivity and reactivity will affect the impact of exposure to chronic stressors on an individual. Such individual differences in stress resilience can occur as a result of differences in either genes and/or developmental experience (for a review, see Ebner \& Singewald 2017). For example, Zebra finches (Taeniopygia guttata) exposed to increased levels of corticosterone as chicks showed exaggerated and prolonged responses to acute stress at 60 days of age (Spencer et al 2009). Stress-resiliency may also vary between and within individuals as a consequence of variation in non-stressful components of their adult exposome that moderate the impact of stressful components. For example, the cellular damage caused by exposure to major life stressors, was diminished in women who did more physical activity, had better quality sleep and ate healthier diets (Puterman et al 2015). Finally, animals can learn about repeated events, either habituating, meaning that successive exposures to the same event result in less impact, or sensitising, meaning that successive exposures result in an increased impact. There are also unlearnt, age-related changes in responsiveness to the external environment that occur as a result of either maturation or senescence. For example, the glucocorticoid response to acute stress has been found to change with age in many species (eg Lendvai et al 2015).

In summary, it is important to distinguish between everything an animal is exposed to during its lifetime - its exposome - and the lasting impact of these exposures on its

\section{Figure I}

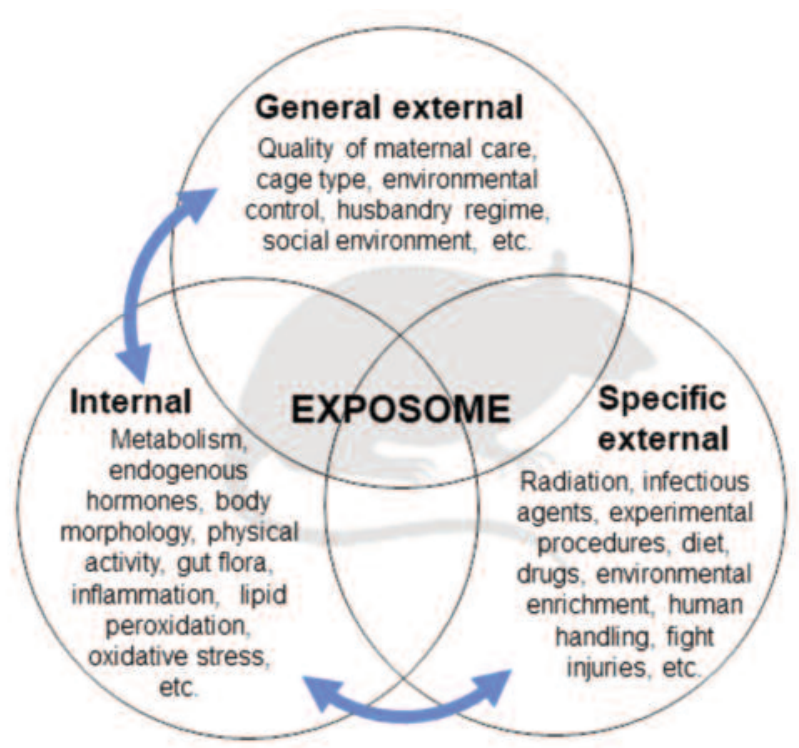

The concept of the 'exposome' for a laboratory animal (adapted from Wild's [2012] original diagram for the human). The three domains of the exposome distinguished by Wild are presented with non-exhaustive examples. The domains are shown as overlapping to indicate that it will not always be possible to allocate an exposure to a single domain. The arrows are our own additions. They indicate that exposures internal to the body will, at least partially, be a response to external exposures and internal exposures will sometimes, via changes in behaviour, bring about changes in external exposures.

health and well-being - its cumulative experience. Not all external exposures will produce changes in internal exposures, and not all internal exposures will leave a lasting impact on somatic state. Furthermore, the impact of a given external exposure could vary between or within individuals. If follows that cumulative experience cannot be assessed by simply quantifying an animal's exposome, or even those specific exposures that are known to have impacts on some individuals. Good measures of cumulative experience should involve assessing an individual animal's response to its exposome.

\section{Biological age and cumulative experience}

What changes in somatic state reflect an animal's response to its exposome? In 1956, stress biologist Hans Selye made the observation that:

Every stress leaves an indelible scar, and the organism pays for its survival after a stressful situation by becoming a little older (Selye 1956)

This quote sets up the hypothesis that there are causal links between the exposome, specifically those components of it that are stressful, and the rate of ageing. Henceforth, we define a stressful exposure as one that is experienced with acute negative affective valence (ie a negative emotional response, such as fear, pain or extreme hunger).

To unpack Selye's observation it is first necessary to understand what ageing is. Ageing is associated with accumulation of molecular damage that has knock-on effects at the cellular, 
Figure 2
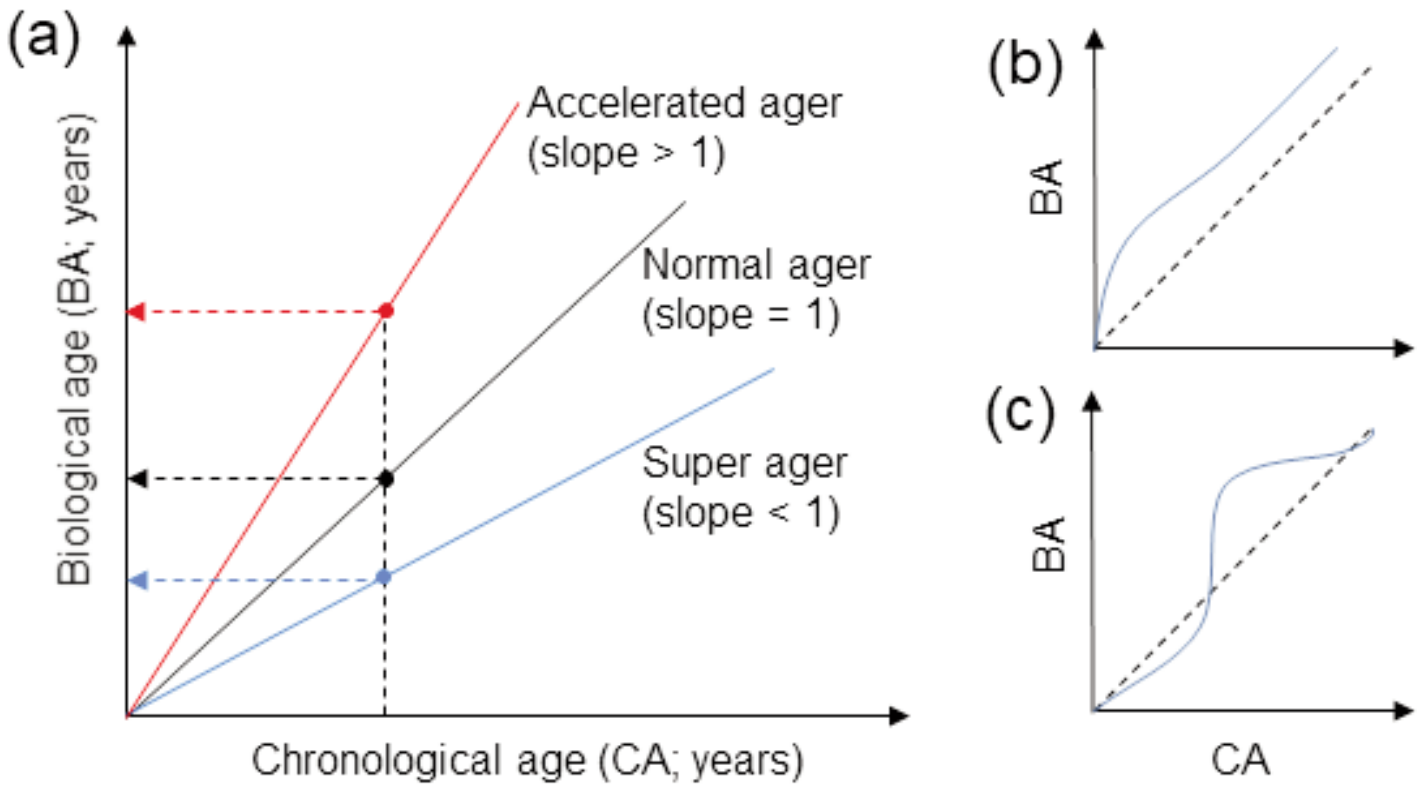

CA

The concept of biological age (adapted from Khan et al 2017). (a) The solid lines show the relationship between chronological age (CA) and biological age (BA) for three different individuals, a super ager (blue), a normal ager (black) and an accelerated ager (red); at a given $C A$, indicated by the vertical dashed line, these three individuals have different BA, indicated by the arrows. Although the functions relating $C A$ to $B A$ are shown as straight lines, there is no reason to assume that the trajectory for a specific individual should be a straight line: an individual's pace of ageing could change with age: (b) shows the BA trajectory for an individual that ages rapidly early in life, but then slows to the normal rate of ageing in adulthood, and (c) shows a more complex trajectory for an individual with periods of both accelerated and super ageing. In panels (b) and (c) the dashed line indicates normal ageing for the population.

\section{Figure 3}

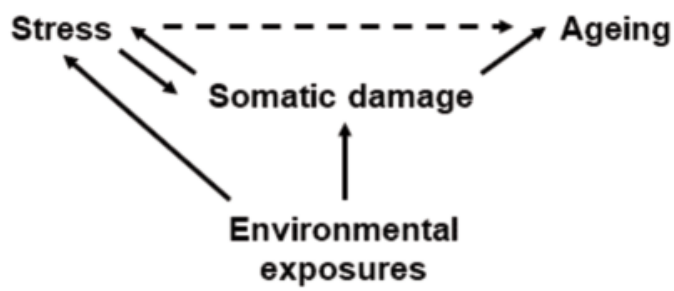

Pathways connecting stress and ageing. The dashed line indicates the association referred to by Selye (1956) and the solid arrows indicate established causal relationships. Selye's association between stress and ageing is explained by a direct causal pathway (stress $\rightarrow$ somatic damage $\rightarrow$ ageing) or via an indirect pathway (stress $\leftarrow$ somatic damage $\rightarrow$ ageing) through somatic damage. Environmental exposures cause stress either directly or via somatic damage.

tissue and whole-organism levels. In terms of function, ageing manifests itself as a decreased ability to maintain homeostasis under stress resulting in increased morbidity and mortality. Ageing occurs with time in all individuals of most species (Nussey et al 2013), but within species there is individual variation in the pace of ageing, resulting in variation in health and mortality for individuals of the same chronological age (eg Lemaitre et al 2013). This variation has led to the concept of biological age as distinct from chronological age (Figure 2). Super agers have better health and lower mortality than would be expected for their chronological age, whereas accelerated agers have poorer health and higher mortality than would be expected for their chronological age (Khan et al 2017). Normal ageing for a given population is determined by measuring the mean rate of ageing in a large sample of individuals. Thus, biological age is always a relative measure, and its interpretation will depend on the sample used to establish it. Variation in biological age within a population can be quite dramatic: for example, Belsky et al (2015) have estimated a biological age range of between 28 and 61 years for a cohort of 38-year old New Zealanders.

What leads to variation in biological age? The heritability of human lifespan has recently been estimated at only $16 \%$ (Kaplanis et al 2018), suggesting that the majority of variation in lifespan is explained by the environment of an individual and hence some components of its exposome. Since biological age predicts life expectancy, the low heritability of lifespan suggests that much of the variation in biological age is also determined by the exposome of an individual. The low heritability of lifespan therefore supports Selye's idea that lifetime exposures can be ageing. Following on from the definition of ageing as accumulation of somatic damage, exposures that result in damage will accelerate ageing, whereas exposures that mitigate the effects of ageing exposures or result in somatic repair will slow or even reverse ageing.

Returning to Selye's observation, why should those exposures that cause somatic damage, and are hence ageing, also be those that are stressful (ie associated with acute negative affective experiences)? There are two pathways that are responsible for the association between stress and ageing, one direct causal pathway and one indirect pathway 
Positive experiences:

- Friends; sexual partners

- Safe environment

Negative experiences:

- Comfortable environment

- Fights; social isolation

- Sufficient, nutritious food

- Dangerous environment

- Uninterrupted sleep

- Uncomfortable environment

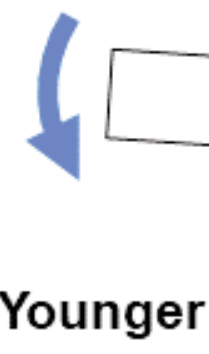

- Poor diet or insufficient food

- Interrupted sleep

\section{Younger}

\section{BIOLOGICAL AGE}

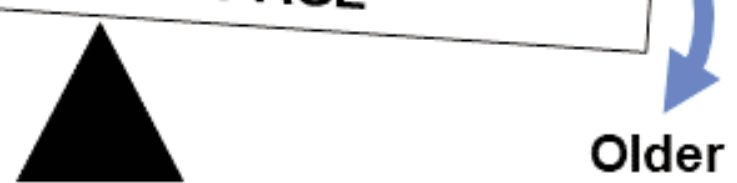

Biological age as a common currency that integrates the impact of multiple different experiences. The impact of negative experiences will be moderated by stress-resilience. Biological age is represented by the angle of the bar. A horizontal bar is assumed to represent a normal ager. Exposure to positively valenced experiences, which are either rejuvenating or moderate the damage caused by negative experiences, shifts the balance towards a biologically younger phenotype (super ager), whereas exposure to negatively valenced experiences, which are typically ageing, shifts the balance towards a biologically older phenotype (accelerated ager - shown here). Details of which exposures are important and the direction of their impact will obviously depend critically on the evolutionary ecology of the species under consideration.

(Figure 3). The indirect association is brought about by the evolutionary function of acute affective (emotional) states. Emotions are an integral part of the psychological machinery that motivates adaptive behaviour. Negative emotional reactions to events function to inhibit behaviour that reduces Darwinian fitness (by minimising exposure to punishers), whereas positive emotional reactions function to promote behaviour that increases fitness (by increasing exposure to rewards: Nettle \& Bateson 2012; Rolls 2013). Since somatic damage is typically fitness-reducing and regeneration and repair are typically fitness-enhancing, we predict those exposures that accelerate ageing to also typically be those exposures that are negatively valenced in terms of the acute affective experience they invoke (ie punishers), whereas those exposures that retard ageing or are rejuvenating will typically be those that are positively valenced (ie rewards). (We discuss exceptions to this general rule in the following section).

In Figure 4, we list some of the exposures that have been shown to be associated with estimates of biological age in humans (for references, see Table 1). Exposures associated with ageing include: psychosocial stress, an environment that is perceived as dangerous, an environment that is physically uncomfortable, inadequate food or interrupted sleep. In contrast, exposures associated with slower ageing or rejuvenation include: psychosocial support, a safe, physically comfortable environment, adequate food and uninterrupted sleep. The ageing exposures are typically associated with poorer health and long-term negative affective experience, whereas the rejuvenating exposures are typically associated with better health and long-term positive affective experience.

In humans, there is a relationship between the valence and frequency of acute affective responses to specific events or exposures and longer-term affective states. Individuals that experience more acutely negative responses, and/or fewer acutely positive responses are more likely to develop negatively valenced longer-term states, such as anxiety and depression (for reviews, see Mendl et al 2010; Nettle \& Bateson 2012).

Thus far, we have only made the indirect argument for an association between ageing and stress: both are caused by exposures that are somatically damaging. However, in humans, there is additionally some evidence for a direct causal link between longer-term affective states and ageing. When other potential causes of variation in morbidity and mortality are controlled for, clinical anxiety and depression (which are extreme presentations of chronic negative affective states) are still associated with increased morbidity and mortality, whereas positive affective states are associated with reduced morbidity and mortality (for a review, see Walker et al 2012). Potential mechanisms assumed to underlie a causal effect of longterm affective states on morbidity include changes in immunosuppression (an important factor in increased cancer risk and cardiovascular disease). Depression also directly causes increased morbidity and mortality by increasing self-harm and suicide rates (Walker et al 2012). Thus, there is evidence for both indirect and direct causal links between stress and ageing.

One of the challenges with which we began this essay was the observation that there can be individual differences in how animals react to the same stressor. Interestingly, many of the genetic mutations that are associated with extended lifespan have been found to affect genes involved in how the organism responds to stressors (Kenyon 2010). If genes that confer stress-resilience also confer longevity, this 
Table I Example evidence from humans on the associations between telomere length, hippocampal volume and aspects of cumulative experience.

\begin{tabular}{|c|c|c|c|c|}
\hline \multicolumn{4}{|c|}{ Type of validity Criteria for validity for biomarker Telomere length (TL) } & \multirow{2}{*}{$\begin{array}{l}\text { Hippocampal volume (HV) } \\
\text { - Perceived stress is associated } \\
\text { with smaller HV (Zimmerman et a } \\
2016)\end{array}$} \\
\hline \multirow[t]{4}{*}{$\begin{array}{l}\text { Construct } \\
\text { validity }\end{array}$} & $\begin{array}{l}\text { I. Biomarker reflects } \\
\text { subjective experience } \\
\text { of stress exposure }\end{array}$ & & $\begin{array}{l}\text { - Perceived stress is associated with TL } \\
\text { (Mathur et al 20I5)* } \\
\text { - Perceived neighbourhood quality is } \\
\text { associated with TL (Park et al 20I5) }\end{array}$ & \\
\hline & $\begin{array}{l}\text { 2. Biomarker covaries } \\
\text { with positive and } \\
\text { negative experience in } \\
\text { opposite directions }\end{array}$ & $\begin{array}{l}\text { Positive } \\
\text { experiences }\end{array}$ & $\begin{array}{l}\text { - Physical activity associated with longer } \\
\text { TL (Mundstock et al 20I5)* } \\
\text { - Healthy lifestyle mitigates stress-induced } \\
\text { telomere attrition (Puterman et al 20I5) } \\
\text { - Mindfulness-based cancer recovery and } \\
\text { supportive-expressive group therapy } \\
\text { associated with reduced telomere attrition in } \\
\text { cancer patients (Carlson et al 20I5) }\end{array}$ & $\begin{array}{l}\text { - Aerobic exercise associated with } \\
\text { larger HV (Firth et al 2018)* } \\
\text { - Healthy diet associated with } \\
\text { larger HV (Jacka et al 20 I5) } \\
\text { - Mindful meditation associated } \\
\text { with larger HV (Luders et al 2009; } \\
\text { Hölzel et al 20II) }\end{array}$ \\
\hline & & $\begin{array}{l}\text { Negative } \\
\text { experiences }\end{array}$ & $\begin{array}{l}\text { - Childhood trauma associated with } \\
\text { shorter TL (Li et al 20I7)* } \\
\text { - Chronic pain is associated with shorter } \\
\text { TL (Hassett et al 20I2) } \\
\text { - Sleep apnoea associated with shorter TL } \\
\text { (Huang et al 20I7)* } \\
\text { - All causes of stress and adversity are } \\
\text { associated with shorter TL } \\
\text { (Pepper et al 20I8) }\end{array}$ & $\begin{array}{l}\text { - Childhood trauma associated with } \\
\text { smaller HV (Paquola et al 2016)* } \\
\text { - Chronic pain associated with } \\
\text { smaller HV (Ezzati et al 20I4; } \\
\text { Niddam et al 20I7) } \\
\text { - Excessive daytime sleepiness } \\
\text { associated with smaller HV (Sforza } \\
\text { et al 2016) }\end{array}$ \\
\hline & $\begin{array}{l}\text { 3. Biomarker integrates } \\
\text { experience(s) over time } \\
\text { (effects of frequency } \\
\text { and/or duration of } \\
\text { events) }\end{array}$ & & $\begin{array}{l}\text { - Number of years as a care-giver is } \\
\text { associated with shorter TL } \\
\text { (Epel et al 2004) }\end{array}$ & $\begin{array}{l}\text { - Time in institutional care as a } \\
\text { child associated with decreased } \\
\text { HV (Hodel et al 20I5) } \\
\text { - Number and frequency of traumatic } \\
\text { events associated with decreased HV } \\
\text { (Dannlowski et al 20I2) }\end{array}$ \\
\hline $\begin{array}{l}\text { Criterion } \\
\text { validity }\end{array}$ & $\begin{array}{l}\text { 4. Biomarker covaries } \\
\text { with measures of } \\
\text { mood }\end{array}$ & & $\begin{array}{l}\text { - Anxiety is associated with shorter TL } \\
\text { (Darrow et al 2016)* } \\
\text { - Post-traumatic stress disorder is associated } \\
\text { with shorter TL (Darrow et al 2016)* } \\
\text { - Depression is associated with shorter TL } \\
\text { (Schutte \& Malouff 20I5; Darrow et al } \\
\text { 2016; Lin et al 2016)* }\end{array}$ & $\begin{array}{l}\text { - Paediatric anxiety is associated } \\
\text { with smaller HV (Gold et al 20I7) } \\
\text { - Post-traumatic stress disorder is } \\
\text { associated with smaller HV } \\
\text { (Woon et al 20I0; O'Doherty et al } \\
\text { 20I5)* } \\
\text { - Depression is associated with } \\
\text { smaller HV (Koolschijn et al 2009; } \\
\text { McKinnon et al 2009; Arnone et al } \\
\text { 2016; Wise et al 2017) }\end{array}$ \\
\hline
\end{tabular}

${ }^{\dagger} \mathrm{HV}$ refers to either amount (or concentration) of hippocampal grey matter or hippocampal volume.

* Indicates that the paper cited is a meta-analysis of multiple empirical studies.

further supports Selye's observation of a connection between exposure to stressful experiences and ageing.

In summary, Selye (1956) suggested that stressful experiences cause accelerated ageing. His observation is supported by more recent research on the biology of stress and ageing. Based on this evidence, we propose that the biological age of an animal could be used to assess its cumulative experience. Biological age can be thought of as a common currency, measured in units of time, that integrates multiple different somatic impacts taking into account variation between and within individuals in stress resiliency. We predict that animals that are biologically old for their chronological age are likely to have had relatively worse lives, both in terms of health and affective state, compared with animals that are biologically younger.

\section{Potential criticisms of the biological age hypothesis}

While the idea of using biological age in a welfare context is new, longevity has been considered and applied previously (eg Morris et al 1998; Clubb et al 2008). Given the close connections between biological age and longevity, it makes sense to revisit previous work on longevity and the criticisms that have been raised to it. We have found two papers that explicitly consider the use of longevity as a welfare indicator. Hurnik and Lehmann (1985) discussed the problem of how different dimensions of welfare (needs) should be weighted in welfare assessment. They argued that longevity is a single objective variable that naturally integrates how well an animal's needs have been met over its lifetime. More recently, Walker et al (2012) discussed how the past affective states of animals can be assessed. They argued, based on empirical evidence for causal links 
between affective state and morbidity and mortality, that longevity could be used to assess past affective state. Various objections have been raised to the hypothesis that longevity is a potentially useful welfare indicator, both by the authors of these latter papers themselves and by other commentators (eg Fraser 1995). If we think of welfare assessment as a classification problem, then two types of errors are possible. False negative errors occur if using longevity causes us to miss cases of true poor welfare; whereas false positive errors occur if using longevity causes us to infer poor welfare when true welfare is in fact good. A high false negative rate implies that longevity has poor sensitivity as a measure of welfare, whereas a high false positive rate implies that it has poor specificity. Since the various criticisms of longevity all concern the possibility of either false negative or false positive errors, we categorise the objections according to the type of error involved.

\section{Longevity is insensitive}

First, assessing cumulative experience based on longevity could miss cases of poor welfare in animals that are killed young rather than being allowed to live out their natural lifespans. This could occur because differences in longevity are often not manifest until animals become old. While this is a limitation of using actual longevity, our suggestion of assessing biological age as opposed to longevity provides a solution. It has become clear that variance in biological age is present even in populations that are currently young and ostensibly healthy (eg Belsky et al 2015), meaning that there is no need to wait until animals die to assess the impact of their exposome.

Second, assessing cumulative experience based on longevity could miss cases of poor welfare in animals whose lives are artificially prolonged by modern medical treatments. This could occur because such treatments break the natural link between cumulative experience and longevity. As with the previous objection, this problem is likely to be addressed by using biological age in place of longevity to assess cumulative experience. Unless lifeextending medical interventions are actually rejuvenating, reversing the somatic damage that has led to disease, we predict that sick animals kept alive by modern medicine will, on average, have greater biological age than otherwise matched healthy animals.

Third, assessing cumulative experience based on longevity could miss cases of poor welfare in populations in which a substantial source of mortality is unrelated to ageing. In such cases, the non-ageing-related mortality will be a source of noise that will mask ageing-related mortality, leading to false negative errors. Fraser (1995) used the following thought experiment to dismiss the premise that those factors truly important for quality of life are also those that promote longevity:

If prisoners on average live longer than owners of small aircraft, few would argue that this necessarily indicates greater quality of life

The argument here is presumably that owners of small aircraft will have better welfare than prisoners due to being free and well-off financially, but reduced longevity due to their higher probability of being killed in an accident. In this specific example, we question the assumption that humans forced to live in the sub-optimal environment of a prison would actually, on average, live longer than humans that voluntarily partake in sports with an additional likelihood of accidental death. Prisoners might be less likely to die in plane crashes, but they will be more likely to suffer stressrelated morbidity and mortality. Moreover, even if the true difference in longevity was, as Fraser suggested, the problem will again be addressed by using biological age in place of longevity to assess cumulative experience. We predict that, on average, the biological age of prisoners is likely to be greater than that of participants in dangerous sports (we found one paper showing increased biological age in ex-prisoners of war compared to matched controls that had military service but were not held captive (Solomon et al 2017), but no one seems to have assessed biological age in owners of small aircraft yet).

In summary, concerns that longevity will be an insensitive measure of cumulative experience, missing true cases of poor welfare, can be addressed by using biological age in place of longevity.

\section{Longevity is non-specific}

Possibly the most difficult objection to the hypothesis that longevity or biological age can be used to assess cumulative experience is the apparent existence of situations in which the assumed association between acute negative affective state and accelerated ageing is reversed and acute positive affect appears to be related with accelerated ageing. If such situations exist, then there is a concern that assessing cumulative experience based on either longevity or biological age would result in false positive detection of poor welfare when true welfare is in fact good.

There are at least two categories of situations in which animals are motivated to behave in ways that will result in accelerated ageing. The first arises as the result of evolutionary mismatches between animals' motivational systems and their current environment. Such mismatches arise with substances, such as alcohol, drugs of abuse and high-sugar foods that were either not present, or much rarer, or less concentrated in the environment of evolutionary adaptedness. Consumption of these substances triggers evolved reward pathways leading to excessive consumption and causing long-term somatic damage. For example, excessive alcohol consumption, smoking and drinking of sweetened beverages are all associated with increased biological age (Strandberg et al 2012; Astuti et al 2017; Rafie et al 2017; Wojcicki et al 2018).

The second situation arises when an individual's inclusive fitness is maximised by behaviour that increases its own morbidity or mortality. The most obvious examples occur in relation to reproduction (Fraser 1995; Barnard \& Hurst 1996). Reproduction is a vital component of Darwinian fitness, but comes at a cost to future morbidity and mortality (for reviews, see Harshman \& Zera 2007; Nussey et al 2013). Thus, animals should be highly motivated to reproduce and should find exposures related 
to reproduction rewarding, but reproduction is associated with accelerated ageing. This cost of reproduction has been documented in several species. For example, in red deer (Cervus elaphus) and badgers (Meles meles), individuals that invest more in reproduction age more quickly (Nussey et al 2006; Beirne et al 2015).

The above situations might seem problematic for the hypothesis that longevity or biological age can be used to assess cumulative experience because these measures lack specificity. However, in the case of both taking drugs and having sex, although the short-term affective consequences may be positive, both behaviours have medium-term consequences that are negative. Thus, the short-term positive affect from taking drugs may be offset by later negative affect arising from comedown, hangovers and withdrawal. Similarly, the short-term positive affect from having sex may be offset by the later negative affect arising from childbearing (nausea, pain) and increased exposure to a variety of stressors associated with child-rearing (post-natal depression, lack of sleep, increased work, financial stresses). Confirming the suggestion that the net effect of reproduction on long-term affective state in humans is negative, many studies have found that overall affective state is more positive in childless couples compared with those with children (eg Glass et al 2016).

In summary, while there are undoubtedly situations (specifically in relation to drugs and sex) where animals are motivated to engage in behaviour that accelerates biological ageing, it is an empirical question how these behaviours affect their cumulative experience. There is evidence to suggest that the acute positive affect arising from taking drugs or having sex is offset by later negative affect arising as a direct consequence of these activities. Therefore, we argue that there is currently no strong evidence against our prediction that individuals that are biologically old for their chronological age will, on average, have experienced worse lives overall than individuals that are biologically younger. In general, we believe that exposures that cause somatic damage, and are hence bad for health, will also be those that are associated with more negatively valenced long-term affective states. Thus, biological age should be a relatively specific measure of cumulative experience.

\section{Biomarkers}

A biomarker is an objectively quantifiable biological trait that can be used to identify or predict a pathological process. We have criticised previous attempts to use single biomarkers, such as bodyweight or cortisol levels in the assessment of cumulative experience. In the current section we start by considering the criteria that a biomarker of cumulative experience should meet. We then go on to describe biomarkers of biological age and suggest two specific biomarkers that we argue meet these criteria.

\section{Validating biomarkers of cumulative experience}

Our discussion in the second and third sections of this essay suggests four criteria that should be met by a biomarker of biological age if it is to serve as a valid measure of cumulative experience. First, the biomarker should reflect an individual's response to their exposome better than mere exposure to it. In humans, one possible strategy for establishing whether this is the case is to ask whether the biomarker covaries with participants' subjective estimates of their experience (eg perceived stress) more strongly than objective measures of what stressors they have been exposed to. Second, the biomarker should covary with good and bad experiences in opposite directions. Unhealthy or negatively valenced experiences should be associated with accelerated ageing, whereas healthy or positively valenced experiences should be associated with slower ageing. Experiences may interact non-additively. For example, a major traumatic experience may increase the ageing impact of smaller subsequent stressors, or healthy/positively valenced experiences may reduce the ageing impact of unhealthy/negatively valenced experiences. Moderating effects of this type would be reflected in interactions between the effects of good and bad experience on ageing. Third, the biomarker should integrate experiences over time and hence reflect the overall balance of unhealthy/negatively valenced experience versus healthy/positively valenced experiences. One strategy to demonstrate temporal integration is to ask whether the biomarker responds in a dose-dependent fashion to the frequency and duration of events experienced. There is no reason to assume that such effects will be linear: an individual might respond more or less to successive exposures to an identical stressor. A second strategy is to ask whether exposures from the distant past have a lasting impact on the biomarker; we would expect traumatic experiences to leave a lasting 'scar'. These first three criteria all follow from the simple theoretical model outlined in Figure 4 and thus comprise what is referred to as 'construct validity' (Cronbach \& Meehl 1955; Trochim et al 2015).

'Criterion validity' relates to the correlation between the biomarker and an existing measure considered to be the current gold standard (Cronbach \& Meehl 1955; Trochim et al 2015). As discussed earlier, there is currently no gold standard measure of cumulative experience in any species. However, human moods are relatively enduring affective states that are sensitive to the positive and negative experiences of an individual over time (Mendl et al 2010; Nettle $\&$ Bateson 2012). Various types of stress including physical and emotional neglect, abuse and trauma, especially when experienced early in life, are associated with subsequent lifelong increased vulnerability to mood disorders, such as anxiety and depression (Heim \& Nemeroff 2001; Weich et al 2009; Pechtel \& Pizzagalli 2011). As discussed earlier, negatively valenced mood can also directly cause somatic damage (Walker et al 2012). Mood is therefore closely 
linked to the concept of cumulative experience and we argue that self-reported measures of mood can be used to validate candidate biomarkers of cumulative experience in humans (Bateson 2016; Poirier et al 2018). There exists an extensive literature documenting the associations between clinical anxiety and depression and a range of somatic variables including biomarkers of biological age. These extreme presentations of negative affective states can be used for establishing the criterion validity of a candidate biomarker in humans. The fourth criterion for validity is, therefore, that a biomarker of cumulative experience should covary with measures of mood in humans.

From an applied perspective, a practical biomarker of cumulative experience should additionally be one that can be measured cheaply and non-invasively in vivo with low measurement error. In practice, there often seem to be trade-offs between these characteristics, as we discuss further below.

\section{Biomarkers of biological age}

A biomarker of biological age is a trait that is correlated with chronological age, but predicts morbidity and mortality better than chronological age (Jylhava et al 2017; Khan et al 2017). Biological age is measured using one or more biomarkers. In humans, a number of different candidate biomarkers of biological age have been identified including 'epigenetic clocks', leukocyte telomere length, 'brainpredicted age' derived from structural neuroimaging, transcriptomic predictors, proteomic predictors and metabolomics-based predictors (Jia et al 2017; Cole et al 2018). These different biomarkers are typically not perfectly correlated with each other (Jylhava et al 2017; Cole et al 2018). Low correlation can occur as a result of measurement error in one or more of the biomarkers and may also occur if different biomarkers respond to different types of exposure and are thus sensitive to different causes of ageing. It is possible that some ageing biomarkers may respond to specific types of exposure, whereas others may respond to multiple different types of exposure. These latter problems are sometimes solved by using two or more biomarkers to estimate biological age. If the measurement errors for different biomarkers are uncorrelated, then triangulation with more than one biomarker will provide a more accurate estimate of the underlying latent variable being estimated (Munafò \& Smith 2018). In an example of the latter strategy, Belsky et al (2015) used a panel of 18 biomarkers (including waist-hip ratio, mean arterial pressure, leukocyte telomere length and white blood cell count) to estimate variation in ageing in a cohort of healthy humans.

Not all biomarkers of biological age will provide equally good biomarkers of cumulative experience. We need a biomarker that responds to multiple different types of exposure and that meets the four criteria outlined above. Thus far, we have identified two plausible candidates: leukocyte telomere length (henceforth TL) and hippocampal volume or, alternatively, the local amount of grey matter in the anterior hippocampus (henceforth HV). Identification of novel biomarkers of ageing is a rapidly evolving field and we do not want to give the impression that TL and HV are the only two biomarkers worth considering for assessing cumulative experience. However, at the time of writing there is far more data available on TL and HV than for other potential biomarkers.

In the paragraphs that follow we briefly describe TL and $\mathrm{HV}$ for readers not familiar with them and provide an overview of the evidence suggesting that they are valid biomarkers of cumulative experience in humans. Since we have reviewed the evidence linking these biomarkers to cumulative experience in non-human animals in detail elsewhere (Poirier et al 2018; Bateson 2016 for TL) we do not repeat this information here.

\section{Telomere length ( $\mathrm{TL})$}

Telomeres are the DNA-protein complexes at the ends of chromosomes that function to protect coding regions of DNA from damage. TL is a molecular measure that estimates the length in base pairs of the protective telomeric DNA sequence. TL in humans is typically measured in leukocytes obtained from blood samples or occasionally in buccal cells obtained from cheek swabs. Telomere length can be measured via a range of established protocols, the cheapest and most common of which is a qPCR (quantitative polymerase chain reaction)-based method that measures the amount of telomeric sequence in a sample relative to the amount of a chosen single-copy gene (for a review of TL measurement methods, see Nussey et al 2014). A major limitation with TL is the magnitude of measurement error; this can be considerable and varies between protocols with qPCR measures often emerging as the least precise (Aviv et al 2011; Bateson et al 2018).

As required of a biomarker of biological age, TL decreases with chronological age (Müezzinler et al 2013) and predicts longevity better than chronological age (eg Kimura et al 2008). Table 1 summarises selected evidence from humans suggesting that TL also meets the four criteria for validity as a measure of cumulative experience outlined above. However, some caution is warranted. A recent major metaanalysis showed that while many different forms of stress and adversity (including physical disease, environmental toxins, poor nutrition, poor sleep, less physical activity, psychosocial stressors and low socioeconomic status) are associated with shorter TL in humans, the effect size is small and most studies are underpowered (Pepper et al 2018). Thus, large sample sizes are likely to be required to avoid false negative results. A second problem arises from the fact that the majority of the TL studies cited in Table 1 are based on cross-sectional correlational data. In the absence of more longitudinal studies, or better still, randomised controlled trials, it is impossible to infer whether the correlations between exposures and TL are causal. Although it is widely assumed that exposure to stressors of various types accelerates telomere attrition, the evidence that this is true in vivo is currently surprisingly weak (Bateson et al undated, 2018; Bateson \& Nettle 2018). Whilst there is some evidence that telomeres can lengthen, and that health behaviours may moderate telomere attrition or promote repair, the evidence is currently controversial 
(Steenstrup et al 2013; Bateson \& Nettle 2017). Thus, although the evidence presented in Table 1 looks promising, further work is needed to establish the causal links between cumulative experience and telomere attrition in humans.

Telomeres are present in all eukaryotic organisms, and the human telomeric DNA sequence, TTAGGG, is conserved across the vertebrates. While there is variation between vertebrate species in telomere biology that is likely to affect telomere dynamics (Gomes et al 2010, 2011), there is mounting evidence that non-human primates and birds share similar dynamics to those in humans (for a review, see Bateson 2016). Supporting the extension of TL to nonhuman species, a recent meta-analysis found that as in humans, short telomere length is associated with increased risk of mortality in a range of vertebrate species including sheep, several birds and three reptile species (Wilbourn et al 2018). In one of the first welfare-focused applications, a recent study of dairy cows showed an association between TL in calves and productive lifespan (Seeker et al 2018). Furthermore, there is strong experimental evidence from nestling passerine birds showing that exposure to stressors causes telomere attrition and moreover, that different types of stress are additive in their effects on TL (eg Nettle et al 2017). There are a handful of encouraging experimental studies in other vertebrate species showing that stress causes telomere attrition (for a review, see Bateson 2016), but more work is required to validate TL as a measure of cumulative experience in any single non-human species.

\section{Hippocampal volume (HV)}

The human hippocampal formation (henceforth hippocampus) is a bilateral, oblong, forebrain structure involved in cognition and emotional regulation. There is regional specialisation within the primate hippocampus with the anterior region implicated specifically in emotional regulation. $\mathrm{HV}$ is a macroscopic measure of hippocampal anatomy that can be obtained in vivo using structural neuroimaging techniques such as magnetic resonance imaging (MRI) to assess either total hippocampal volume or the local amount of grey matter in the specific regions of the hippocampus. These different biomarkers are likely to be positively correlated, but the latter biomarker should be more sensitive to cumulative experience because it can be localised to the stress-sensitive anterior region (for a review, see Poirier et al 2018). The greatest practical limitation to the measurement of $\mathrm{HV}$ is access to neuroimaging facilities and the expertise required for data analysis. Measurement error is not discussed as an issue in measurement of $\mathrm{HV}$.

Although HV atrophies with chronological age (Fjell et al 2013), it is not referred to as a biomarker of biological age. There is no evidence available on whether HV specifically predicts mortality better than chronological age, but a brainbased biomarker derived from structural neuroimaging data predicts mortality better than chronological age (Cole et al 2018), suggesting that this might be the case. The evidence summarised in Table 1 suggests that HV meets the four criteria for validity as a biomarker of cumulative experience in humans. As for TL, the studies cited in Table 1 are largely based on cross-sectional correlational data, but the case for a causal relationship between experience and $\mathrm{HV}$ is strong due to the existence of extensive experimental animal data (see below).

The hippocampus is an evolutionarily conserved brain structure, and homologues have been described in all vertebrate lineages (Bingman et al 2009). Furthermore, the regional specialisation, whereby it is the anterior region that is specifically sensitive to stress, has been demonstrated in macaques, rats and mice (with the anterior hippocampus of humans and macaques being homologous to the ventral hippocampus of rodents; [for a review, see Poirier et al 2018]). Due to the strong conservation of hippocampal structure and function in the mammals, the effects of positively and negatively valenced affective experiences on HV have already been studied experimentally in macaques, rats and mice. We have argued elsewhere that there is already sufficient evidence to show that HV meets our criteria for validity as a measure of cumulative experience in these species (Poirier et al 2018).

\section{Comparison of TL and HV as biomarkers of cumulative experience}

The literature summarised in Table 1 shows remarkable similarities in the types of exposures that are associated with TL and HV in humans. If TL and HV are both sensitive to the same aspects of cumulative experience, a positive correlation between TL and HV is predicted. Supporting this prediction, a study of 1,960 middle-aged Americans found that leukocyte TL and hippocampal grey matter volume were positively correlated after controlling for age, total intracranial volume and a number of other covariates (King et al 2014). Furthermore, the pattern of telomerelength-related regional brain volumes overlapped with brain regions associated with stress-related psychopathology more generally (hippocampus, orbitofrontal cortex, insula and anterior cingulate), supporting the hypothesis that TL and HV are both affected by stress. However, a metaanalysis that combined this study with four lower-powered studies only found a non-significant positive association between TL and HV overall (Nilsonne et al 2015). Thus far, only a single study has compared changes in TL and HV longitudinally within the same individuals (Staffaroni et al 2018). This study of 69 functionally normal older adults showed that greater TL shortening over 2.9 years was associated with greater hippocampal volume loss, even after controlling for global grey matter atrophy. Interestingly, this study found no cross-sectional association between baseline $\mathrm{TL}$ and $\mathrm{HV}$, demonstrating the greater power of longitudinal studies in the study of these biomarkers. This latter study provides support for the hypothesis that TL and HV are biomarkers of the same biological processes in humans.

In summary, we have presented evidence that TL and HV both meet our criteria as valid biomarkers of cumulative experience in humans. A major reason for our choosing TL and $\mathrm{HV}$ is that these biomarkers depend on biology that is conserved in non-human vertebrates (although this conservation is stronger for $\mathrm{HV}$ than for TL). TL and HV thus both have potential for use in the assessment of cumulative expe- 
rience in non-human species. Despite some promising results, further work is required to validate TL as a biomarker of cumulative experience in any non-human species. In the case of $\mathrm{HV}$, sufficient validation has already been performed in macaques, rats and mice to justify the use of this biomarker in the assessment of cumulative experience. We suggest that the minimum validation necessary before TL or HV is applied in a new species is to demonstrate, using a randomised control trial, that exposure to a validated stressor (eg something equivalent to chronic mild stress in mice) causes an increase in biological age as measured by the biomarker.

\section{Uses and limitations of biomarkers}

We have argued that it is possible to reduce the complex concept of cumulative affective experience to a single number: the difference between an individual's current biological and chronological age. For many uses of biomarkers in welfare assessment it is not actually necessary to calculate this difference. It is sufficient to compare the value of the biomarker between groups of animals subjected to different exposures (eg Jackowski et al 2011; Aydinonat et al 2014). Alternatively, the longitudinal change in the value of the biomarker can be measured within animals exposed to different experiences (eg Rahman et al 2016; Nettle et al 2017). Between individuals of the same chronological age we predict that those individuals with biomarker values indicative of the oldest biological age will have experienced worse lives than those with the youngest. Within individuals, we predict that a greater increase in biological age as indicated by the change in biomarker values, will be associated with a period of life when experience was worse. In general, we expect longitudinal experimental designs, which measure changes in the value of a biomarker within individuals at two or more points in time, to be the most powerful, because such designs control for individual differences in the value of the biomarkers that will add noise to cross-sectional studies. As a consequence, longitudinal designs will require many fewer subjects than cross-sectional designs to observe a given effect. Indeed, it has been estimated that longitudinal studies of TL require five times less subjects than crosssectional studies (Aviv et al 2006).

While it is possible to use TL and HV to make statements about differences in relative experience (either between individuals or between time-periods), it is important to bear in mind that interpretation of absolute TLs or HVs is more problematic. Just because an animal falls in the longest quartile of TL for the sample measured says nothing about the absolute quality of its experience, because the mean of a sample depends on the sample chosen. Even if it was possible to say that, on average, an animal reared under a given husbandry regime is aged by two years compared to an animal reared under a different regime, it is unclear what this means in terms of absolute differences in welfare. This raises the question of how we benchmark or calibrate values of a biomarker. What values are unacceptable from a welfare perspective? In humans, one approach would be to use the magnitude of changes in biomarkers associated with clinical conditions, such as major depressive disorder or generalised anxiety disorder that we know are associated with substantial suffering. This approach could be extended to non-human animals by using the biomarker values observed in validated models of anxiety and depression to benchmark the effect of a given type of exposure (eg Clarkson et al 2018).

More fundamental limitations of the biomarker approach are implicit in reducing cumulative experience to a single number. Much detailed information about an individual's experience is inevitably lost. For example, does it matter if several seemingly innocuous, mildly stressful experiences produce the same effect on a biomarker as one very traumatic experience? Does it matter if the 'scar' from a bad experience fades with time, or is overwritten by a subsequent positive experience? If we believe that variance in individual experience over time is important to well-being, then these questions could potentially be addressed by measuring how biomarkers change longitudinally; an individual could be described both by the current difference between their biological and chronological ages and by the variance in this difference over a series of longitudinal measurements. However, if we believe that accumulated damage to the body is all that is important, then a single measure of current biological age is sufficient. Current biological age should, by definition after all, be a good predictor of future morbidity and mortality.

\section{Animal welfare implications and conclusion}

We have developed the hypothesis that biological age is a common currency that integrates the quality of an animal's cumulative experience over its lifetime. Ageing is the result of the accumulation of somatic damage, and its rate is determined by the balance between exposure to events that cause damage and events that mitigate damage or promote repair. We have argued that exposures that are ageing tend to be associated with negative affective experience, whereas those that are restorative or that slow ageing tend to be associated with positive affective experience. Thus, we predict that individuals that are biologically old for their chronological age are likely to have experienced worse lives than individuals that are biologically younger, both in terms of their health and affective state. Biological age is an attractive measure of cumulative experience for use in an animal welfare context, because unlike any existing measures, it integrates information about health and affective state in a single measure. Most importantly, using biological age to assess cumulative experience requires no subjective decisions to be made about whether and how a given exposure impacts an animal and how different dimensions of welfare should be weighted in the overall welfare assessment. Therefore, biological age is a natural solution to the mathematical integration problem with which we began this essay. Biological age can be measured using a range of 
different biomarkers. We have presented evidence that two biomarkers, namely leukocyte telomere length (TL) and hippocampal volume or local amount of grey matter in the anterior hippocampus (HV) are valid biomarkers of cumulative experience in humans. TL and HV are evolutionarily conserved in other vertebrates and there is already sufficient evidence to warrant using $\mathrm{HV}$ to assess cumulative experience in selected non-human species. Our motivation in writing this essay was to inspire animal welfare scientists to explore the application of these and other biomarkers of biological age in the assessment of cumulative experience.

\section{Acknowledgements}

The ideas in this paper were initially developed under a project grant from the UK's National Centre for the 3Rs (grant number: NC/K000802/1). We thank Dan Weary and the Berlin Institute for Advanced Study (Wissenschaftskolleg $\mathrm{zu}$ Berlin) for the opportunity to further discuss and develop these ideas, Mike Appleby for drawing our attention to Hurnik and Lehmann's 1985 essay on longevity as an objective correlate of animal well-being and Dan Weary, Georgia Mason, Andrea Polanco and two anonymous referees for helpful comments on the manuscript.

\section{References}

Arnone D, Job D, Selvaraj S, Abe O, Amico F, Cheng Y, Colloby SJ, O'Brien JT, FrodI T, Gotlib IH, Ham BJ, Kim MJ, Koolschijn PCM, Périco CAM, Salvadore G, Thomas AJ, Van Tol MJ, van der Wee NJA, Veltman DJ, Wagner G and Mclntosh AM 2016 Computational meta-analysis of statistical parametric maps in major depression. Human Brain Mapping 37: 1393-I404. https://doi.org//0.1002/hbm.23 108

Astuti Y, Wardhana A, Watkins J and Wulaningsih W 2017 Cigarette smoking and telomere length: A systematic review of 84 studies and meta-analysis. Environmental Research 158: 480489. https://doi.org/10.1016/j.envres.2017.06.038

Aviv A, Hunt SC, Lin J, Cao X, Kimura M and Blackburn E 201 I Impartial comparative analysis of measurement of leukocyte telomere length/DNA content by Southern blots and qPCR. Nucleic Acids Research 39: el 34. https://doi.org//0.1093 /nar/gkr634

Aviv A, Valdes AM and Spector TD 2006 Human telomere biology: Pitfalls of moving from the laboratory to epidemiology. International Journal of Epidemiology 35: I424-I429. https://doi.org//0.1093/ije/dyll69

Aydinonat D, Penn DJ, Smith S, Moodley Y, Hoelzl F, Knauer F and Schwarzenberger F 2014 Social isolation shortens telomeres in African Grey parrots (Psittacus erithacus erithacus). PLoS One 9: 2-6. https://doi.org//0.137I /journal.pone.0093839

Barnard CJ and Hurst JL 1996 Welfare by design: The natural selection of welfare criteria. Animal Welfare 5: 405-433

Bateson M 2016 Cumulative stress in research animals: Telomere attrition as a biomarker in a welfare context? BioEssays 38: 20I-2I2. https://doi.org//0.1002/bies.20I500I 27
Bateson M, Aviv A, Bendix L, Benetos A, Ben-Shlomo Y, Bojesen SE, Cooper C, Cooper R, Deary IJ, Hägg S, Harris SE, Kark JD, Kronenberg F, Kuh D, Labat C, Martin-Ruiz C, Meyer C, Nordestgaard BG, Penninx BWJH, Pepper G, Révész D, Said MA, Starr JM, Syddall $H$, Thomson WM, van der Harst $P$, Whooley $M$, von Zglinicki T, Willeit P, Zhan $\mathbf{Y}$ and Nettle $\mathbf{D}$ undated Smoking does not accelerate leukocyte telomere attrition: a meta-analysis of 18 longitudinal cohorts. Royal Society Open Science. https://doi.org// 0.528I/zenodo. I 46397|

Bateson M, Eisenberg DTA and Nettle D 2018 Controlling for baseline telomere length biases estimates of the rate of telomere attrition. Zenodo. http://doi.org// 0.528I/zenodo. 1009086

Bateson $M$ and Nettle D 2017 The telomere lengthening conundrum - it could be biology. Aging Cell 16(2): 312-319. https://doi.org//0.1 I I I/acel. 12555

Bateson M and Nettle D 2018 Why are there associations between telomere length and behaviour? Philosophical Transactions of the Royal Society of London. Series B, Biological Sciences 373 : 20160438. https://doi.org/I0.1098/rstb.2016.0438

Beirne C, Delahay R and Young A 2015 Sex differences in senescence: The role of intra-sexual competition in early adulthood. Proceedings of the Royal Society B: Biological Sciences 282: 20I5I086. https://doi.org//0.1098/rspb.20I5.1086

Belsky DW, Caspi A, Houts R, Cohen HJ, Corcoran DL, Danese A, Harrington H, Israel S, Levine ME, Schaefer JD, Sugden K, Williams B, Yashin AI, Poulton R and Moffitt TE 2015 Quantification of biological aging in young adults. Proceedings of the National Academy of Sciences I I 2: E4 I 04E4I I0. https://doi.org/ I0.1073/pnas. I506264III2

Bingman VP, Salas C and Rodriguez F 2009 Evolution of the hippocampus. In: Binder MD, Hirokawa $N$ and Winhorst $U$ (eds) Encyclopedia of Neuroscience PP 1356-1360. Springer-Verlag: Berlin, Heidelberg, Germany. https://doi.org/I0.1007/978-3-54029678-2_3158

Carlson LE, Beattie TL, Giese-Davis J, Faris P, Tamagawa R, Fick LJ, Degelman ES and Speca M 2015 Mindfulness-based cancer recovery and supportive-expressive therapy maintain telomere length relative to controls in distressed breast cancer survivors. Cancer I2 I: 476-484. https://doi.org / 0.1002/cncr.29063

Clarkson JM, Dwyer DM, Flecknell PA, Leach MC and Rowe C 2018 Handling method alters the hedonic value of reward in laboratory mice. Scientific Reports 8: 2448. https://doi.org//0.1038/s4I598-018-207/6-3

Clubb R, Rowcliffe M, Lee P, Mar KU, Moss C and Mason GJ 2008 Compromised survivorship in zoo elephants. Science 322: 1649. https://doi.org/I0.1 I 26/science. I 64298

Cole JH, Ritchie SJ, Bastin ME, Valdés Hernández MC, Muñoz Maniega S, Royle N, Corley J, Pattie A, Harris SE, Zhang Q, Wray NR, Redmond P, Marioni RE, Starr JM, Cox SR, Wardlaw JM, Sharp DJ and Deary IJ 2018 Brain age predicts mortality. Molecular Psychiatry 23: I385-1392

Cronbach LJ and Meehl PE 1955 Construct validity in psychological tests. Psychological Bulletin 52: 281-302. https://doi.org /10.1037/h0040957 
Dannlowski U, Stuhrmann A, Beutelmann V, Zwanzger P, Lenzen T, Grotegerd D, Domschke K, Hohoff C, Ohrmann P, Bauer J, Lindner C, Postert C, Konrad C, Arolt V, Heindel W, Suslow T and Kugel H 2012 Limbic scars: Long-term consequences of childhood maltreatment revealed by functional and structural magnetic resonance imaging. Biological Psychiatry 7I: 286-293. https://doi.org/I0.1016/j.biopsych.20II.10.02I

Darrow SM, Verhoeven JE, Révész D, Lindqvist D, Penninx BW, Delucchi KL, Wolkowitz OM and Mathews CA 2016 The association between psychiatric disorders and telomere length: A meta-analysis involving 14,827 persons. Psychosomatic Medicine 78: 776-787. https://doi.org/l0.109 7/PSY.0000000000000356

Dawkins MS 2006 A user's guide to animal welfare science. Trends in Ecology \& Evolution 21: 77-82. https://doi.org/ 10.1016/j.tree.2005.10.017

Dawkins MS 2017 Animal welfare with and without consciousness. Journal of Zoology 30I: I-I0. https://doi.org / I0.1 I I I/jzo. 12434

Ebner K and Singewald N 2017 Individual differences in stress susceptibility and stress inhibitory mechanisms. Current Opinion in Behavioral Sciences 14: 54-64. https://doi.org/10.1016/j.cobeha.2016.11.016

Epel ES, Blackburn EH, Lin J, Dhabhar FS, Adler NE, Morrow JD and Cawthon RM 2004 Accelerated telomere shortening in response to life stress. Proceedings of the National Academy of Sciences of the United States of America 101: 17312173| 5. https://doi.org/ 10.1073/pnas.0407162101

European Parliament and European Council 2010 Directive 2010/63/EU PP 33-79. EU: Brussels, Belgium

Ezzati A, Zimmerman ME, Katz MJ, Sundermann EE, Smith JL, Lipton ML and Lipton RB 2014 Hippocampal subfields differentially correlate with chronic pain in older adults. Brain Research 1573: 54-62. https://doi.org/10.1016/j.brainres.2014.05.025

Farm Animal Welfare Council (FAWC) 2009 Farm Animal Welfare in Great Britain: Past, Present and Future. FAWC: London, UK Firth J, Stubbs B, Vancampfort D, Schuch F, Lagopoulos J, Rosenbaum S and Ward PB 2018 Effect of aerobic exercise on hippocampal volume in humans: A systematic review and meta-analysis. Neurolmage 166: 230-238. https://doi.org /10.1016/j.neuroimage.2017.11.007

Fjell AM, Westlye LT, Grydeland H, Amlien I, Espeseth T, Reinvang I, Raz N, Holland D, Dale AM and Walhovd KB 2013 Critical ages in the life course of the adult brain: Nonlinear subcortical aging. Neurobiology of Aging 34: 2239-2247. https://doi.org//0.1016/j.neurobiolaging.2013.04.006

Fraser D 1995 Science, values and animal welfare: exploring the 'inextricable connection.' Animal Welfare 4: 103-117

Glass J, Simon RW and Andersson MA 2016 Parenthood and happiness: Effects of work-family reconciliation policies in 22 OECD countries. American Journal of Sociology 122: 886-929. https://doi.org// 0.1086/688892

Gold AL, Steuber ER, White LK, Pacheco J, Sachs JF, Pagliaccio D, Berman E, Leibenluft E and Pine DS 2017 Cortical thickness and subcortical gray matter volume in pediatric anxiety disorders. Neuropsychopharmacology 42: 2423-2433. https://doi.org/10.1038/npp.2017.83
Gomes NM, Ryder OA, Houck ML, Charter SJ, Walker W, Forsyth NR, Austad SN, Venditti C, Pagel M, Shay JW and Wright WE 201I Comparative biology of mammalian telomeres: Hypotheses on ancestral states and the roles of telomeres in longevity determination. Aging Cell 10: 761-768. https://doi.org/I0.1 I I I/j. I474-9726.20 I I.007/8.x

Gomes NM, Shay JW and Wright WE 2010 Telomere biology in Metazoa. FEBS Letters 584: 374I-375I. https://doi.org/10.1016/j.febslet.2010.07.031

Gottlieb DH, Capitanio JP and McCowan B 2013 Risk factors for stereotypic behavior and self-biting in rhesus macaques (Macaca mulatta): Animal's history, current environment, and personality. American Journal of Primatology 75: 995-1008. https://doi.org/10.1002/ajp.22161

Greco BJ, Meehan CL, Hogan JN, Leighty KA, Mellen J, Mason GJ and Mench JA 2016 The days and nights of zoo elephants: Using epidemiology to better understand stereotypic behavior of African elephants (Loxodonta africana) and Asian elephants (Elephas maximus) in North American zoos. PLoS One II: I-29. https://doi.org/I0.137//journal.pone.0144276

Harshman LG and Zera AJ 2007 The cost of reproduction: the devil in the details. Trends in Ecology and Evolution 22: 80-86. https://doi.org/10.1016/j.tree.2006.10.008

Hassett AL, Epel E, Clauw DJ, Harris RE, Harte SE, Kairys A, Buyske S and Williams D 2012 Pain is associated with short leukocyte telomere length in women with fibromyalgia. Journal of Pain 13: 959-969. https://doi.org/ 10.1016/j.jpain.2012.07.003

Heim C and Nemeroff CB 200I The role of childhood trau$\mathrm{ma}$ in the neurobiology of mood and anxiety disorders: preclinical and clinical studies. Biological Psychiatry 49: 1023-1039. https://doi.org/I0.1016/S0006-3223(0I)0II57-X

Hodel AS, Hunt RH, Cowell RA, Van Den Heuvel SE, Gunnar MR and Thomas KM 2015 Duration of early adversity and structural brain development in post-institutionalized adolescents. Neurolmage 105: II2-I19. https://doi.org/10.1016/j.neuroimage.20I4.10.020

Hölzel BK, Carmody J, Vangel M, Congleton C, Yerramsetti SM, Gard T and Lazar SW 20II Mindfulness practice leads to increases in regional brain gray matter density. Psychiatry Research - Neuroimaging 191: 36-43. https://doi.org//0.1016/j.pscychresns.2010.08.006

Honess P and Wolfensohn S 2010 The extended welfare assessment grid: A matrix for the assessment of welfare and cumulative suffering in experimental animals. ATLA Alternatives to Laboratory Animals 38: 205-2I2

Huang P, Zhou J, Zhao X, Chen S, Zou C and Li J 2017 The association between obstructive sleep apnea and shortened telomere length: A systematic review and meta-analysis. Sleep Medicine 48: 107-II2. https://doi.org/I0.1016/j.sleep.2017.09.034 Hurnik JF and Lehmann H 1985 The philosophy of farm animal welfare: a contribution to the assessment of farm animal wellbeing. Second European Symposium on Poultry Welfare pp 256-266. Celle, Germany

Jacka FN, Cherbuin N, Anstey KJ, Sachdev P and Butterworth P 2015 Western diet is associated with a smaller hippocampus: a longitudinal investigation. BMC Medicine 13: 215. https://doi.org/I0.1 |86/s12916-015-046I-x 
Jackowski A, Perera TD, Abdallah CG, Garrido G, Tang CY, Martinez J, Mathew SJ, Gorman JM, Rosenblum LA, Smith ELP, Dwork AJ, Shungu DC, Kaffman A, Gelernter J, Coplan JD and Kaufman J 20 I Early-life stress, corpus callosum development, hippocampal volumetrics, and anxious behavior in male nonhuman primates. Psychiatry Research - Neuroimaging 192: 37-44. https://doi.org/10.1016/j.pscychresns.2010.11.006

Jia L, Zhang $\mathbf{W}$ and Chen $\mathbf{X} 2017$ Common methods of biological age estimation. Clinical Interventions in Aging 12: 759-772. https://doi.org/I0.2 I47/CIA.SI3492 I

Jylhava J, Pedersen NL and Hagg S 2017 Biological age predictors. EBioMedicine 21: 29-36. https://doi.org/10.1016 /j.ebiom.2017.03.046

Kaplanis J, Gordon A, Wahl M, Gershowitz M, Markus B, Sheikh M, Gymrek M, Bhatia G, MacArthur DG, Price A and Erlich Y 2018 Quantitative analysis of population-scale family trees using millions of relatives. Science 360: 17I-175. https://doi.org/10.1 I26/science.aam9309

Kenyon CJ 2010 The genetics of ageing. Nature 467: 504-5I 2. https://doi.org/10.1038/nature08980

Khan SS, Singer BD and Vaughan DE 2017 Molecular and physiological manifestations and measurement of aging in humans. Aging Cell 16: 624-633. https://doi.org/I0.1 I I I/acel.1260 I

Kimura M, Hjelmborg JVB, Gardner JP, Bathum L, Brimacombe M, Lu X, Christiansen L, Vaupel JW, Aviv A and Christensen K 2008 Telomere length and mortality: A study of leukocytes in elderly Danish twins. American Journal of Epidemiology 167: 799-806. https://doi.org//0.1093/aje/kwm380

King KS, Kozlitina J, Rosenberg RN, Peshock RM, McColl RW and Garcia CK 2014 Effect of leukocyte telomere length on total and regional brain volumes in a large population-based cohort.. JAMA Neurology 7I(10): 1247-1254. https://doi.org/ 10.1001/jamaneurol.2014.1926

Koolschijn PCMP, van Haren NEM, Lensvelt-Mulders GJLM, Hulshoff Pol HE and Kahn RS 2009 Brain volume abnormalities in major depressive disorder: A meta-analysis of magnetic resonance imaging studies. Human Brain Mapping 30: 37/9-3735. https://doi.org//0.1002/hbm.2080 I

Lemaître JF, Gaillard JM, Lackey LB, Clauss M and Müller DWH 2013 Comparing free-ranging and captive populations reveals intra-specific variation in aging rates in large herbivores. Experimental Gerontology 48: 162-167. https://doi.org/ 10.1016/j.exger.2012.12.004

Lendvai Z, Giraudeau M and Bo V 2015 Within-individual plasticity explains age-related decrease in stress response in a short-lived bird. Biology Letters II: 20150272. https://doi.org/ 10.1098/rsbl.20I5.0272

Li Z, He Y, Wang D, Tang J and Chen X 2017 Association between childhood trauma and accelerated telomere erosion in adulthood: A meta-analytic study. Journal of Psychiatric Research 93: 64-7I. https://doi.org/I0.1016/j.jpsychires.2017.06.002

Lin PY, Huang YC and Hung CF 2016 Shortened telomere length in patients with depression: A meta-analytic study. Journal of Psychiatric Research 76: 84-93. https://doi.org/10.1016/j.jpsychires.2016.01.015

Luders E, Toga AW, Lepore N and Gaser C 2009 The underlying anatomical correlates of long-term meditation: Larger hippocampal and frontal volumes of gray matter. Neurolmage 45: 672-678. https://doi.org/10.1016/j.neuroimage.2008.12.061
Mason GJ and Latham NR 2004 Can't stop, won't stop: Is stereotypy a reliable animal welfare indicator? Animal Welfare 13: 57-69

Mathur MB, Epel E, Kind S, Desai M, Parks CG, Sandler DP and Khazeni N 2015 Perceived stress and telomere length: A systematic review, meta-analysis, and methodologic considerations for advancing the field. Brain, Behavior and Immunity 54: I58169. https://doi.org/10.1016/j.bbi.2016.02.002

McKinnon MC, Yucel K, Nazarov A and MacQueen GM 2009 A meta-analysis examining clinical predictors of hippocampal volume in patients with major depressive disorder. Journal of Psychiatry Neuroscience 3434: 4I-54

Mendl M, Burman OHP, Parker RMA and Paul ES 2009 Cognitive bias as an indicator of animal emotion and welfare: Emerging evidence and underlying mechanisms. Applied Animal Behaviour Science 1/8: 161-181. https://doi.org//0.1016/j.applanim.2009.02.023

MendI M, Burman OHP and Paul ES 2010 An integrative and functional framework for the study of animal emotion and mood. Proceedings of the Royal Society B: Biological Sciences 277: 28952904. https://doi.org/10.1098/rspb.2010.0303

Morozova A, Zubkov E, Strekalova T, Kekelidze Z, Storozeva Z, Schroeter CA, Bazhenova N, Lesch KP, Cline BH and Chekhonin V 2016 Ultrasound of alternating frequencies and variable emotional impact evokes depressive syndrome in mice and rats. Progress in Neuro-Psychopharmacology and Biological Psychiatry 68: 52-63. https://doi.org/10.1016/j.pnpbp.2016.03.003

Morris JR, Hurnik JF, Friendship RM and Evans NM 1998 The effect of the Hurnik-Morris (HM) system on sow reproduction, attrition, and longevity. Journal of Animal Science 76: 27592762. https://doi.org/10.2527/1998.76 I 12759x

Müezzinler A, Zaineddin KA and Brenner H 2013 A systematic review of leukocyte telomere length and age in adults. Ageing Research Reviews 12: 509-519. https://doi.org//0.1016 /j.arr.2013.01.003

Munafò MR and Smith GD 2018 Repeating experiments is not enough. Nature 553: 399-40I. https://doi.org//0.1038/d4I586018-01023-3

Mundstock E, Zatti H, Louzada FM, Oliveira SG, Guma FTCR, Paris MM, Rueda AB, Machado DG, Stein RT, Jones MH, Sarria EE, Barbé-Tuana FM and Mattiello $R$ 2015 Effects of physical activity in telomere length: Systematic review and meta-analysis. Ageing Research Reviews 22: 72-80. https://doi.org/10.1016/j.arr.2015.02.004

Nettle D, Andrews C, Reichert S, Bedford T, Kolenda C, Parker C, Martin-Ruiz C, Monaghan P and Bateson M 2017 Early-life adversity accelerates cellular ageing and affects adult inflammation: Experimental evidence from the European starling. Scientific Reports 7: 40794. https://doi.org//0.1038/srep40794

Nettle D and Bateson M 2012 The evolutionary origins of mood and its disorders. Current Biology 22: R7I2-72I. https://doi.org/10.1016/j.cub.2012.06.020

Niddam DM, Lee S-H, Su Y-T and Chan R-C 2017 Brain structural changes in patients with chronic myofascial pain. European Journal of Pain 2I: 148-I58. https://doi.org//0.1002/ejp.91 I 
Nilsonne G, Tamm S, Månsson KNT, Åkerstedt T and Lekander M 2015 Leukocyte telomere length and hippocampus volume: a meta-analysis. Fl000 Research 4: 1073. https://doi.org/I0.12688/fl000research.7198.I

Nussey DH, Baird D, Barrett E, Boner W, Fairlie J, Gemmell N, Hartmann N, Horn T, Haussmann M, Olsson M, Turbill C, Verhulst S, Zahn S and Monaghan P 2014 Measuring telomere length and telomere dynamics in evolutionary biology and ecology. Methods in Ecology and Evolution 5: 299-3 10. https://doi.org/I0.1 I I /2041-210X.12161

Nussey DH, Froy H, Lemaitre JF, Gaillard JM and Austad SN 2013 Senescence in natural populations of animals: Widespread evidence and its implications for bio-gerontology. Ageing Research Reviews 12: 214-225. https://doi.org /10.1016/j.arr.2012.07.004

Nussey DH, Kruuk LEB, Donald A, Fowlie M and CluttonBrock TH 2006 The rate of senescence in maternal performance increases with early-life fecundity in red deer. Ecology Letters 9: |342-| 350. https://doi.org/ | 0. I | | |/j. | 46 |-0248.2006.00989.x

O'Doherty DCM, Chitty KM, Saddiqui S, Bennett MR and Lagopoulos J 2015 A systematic review and meta-analysis of magnetic resonance imaging measurement of structural volumes in post-traumatic stress disorder. Psychiatry Research Neuroimaging 232: I-33. https://doi.org/10.1016/j.pscychresns.2015.01.002

Paquola C, Bennett MR and Lagopoulos J 2016 Understanding heterogeneity in grey matter research of adults with childhood maltreatment. A meta-analysis and review. Neuroscience and Biobehavioral Reviews 69: 299-312. https://doi.org/I0.1016/j.neubiorev.2016.08.01 I

Park M, Verhoeven JE, Cuijpers P, Reynolds CF and Penninx BWJH 2015 Where you live may make you old: The association between perceived poor neighborhood quality and leukocyte telomere length. PLoS One 10: I-13. https://doi.org /I0.137I/journal.pone.0128460

Paul ES, Harding EJ and Mendl M 2005 Measuring emotional processes in animals: the utility of a cognitive approach. Neuroscience and Biobehavioral Reviews 29: 469-49I. https://doi.org/ 10.1016/j.neubiorev.2005.01.002

Pechtel P and Pizzagalli DA 20I I Effects of early life stress on cognitive and affective function: An integrated review of human literature. Psychopharmacology 2/4: 55-70. https://doi.org /10.1007/s00213-010-2009-2

Pepper GV, Bateson M and Nettle D 2018 Telomeres as integrative markers of exposure to stress and adversity: A systematic review and meta-analysis. Royal Society Open Science. http://rsos.royalsocietypublishing.org/content/5/8//80744

Pickard J 2013 Review of the assessment of cumulative severity and lifetime experience in non-human primates used in neuroscience research. www.gov.uk/government/uploads/system/uploads /attachment_data/file/261687/cs_nhp_review_FINAL_2013_corrected.pdf

Poirier C and Bateson M 2017 Pacing stereotypies in laboratory rhesus macaques: implications for animal welfare and the validity of neuroscientific findings. Neuroscience and Biobehavioral Reviews 83: 508-5I5. https://doi.org/10.1016/j.neubiorev.2017.09.010
Poirier C, Bateson M, Gualtieri F, Armstrong EA, Laws GC, Boswell T and Smulders TV 2018 Validation of a cumulative affective experience biomarker: hippocampal plasticity (Version I). Zenodo. http://doi.org//0.528I/zenodo.2445798

Puterman E, Lin J, Krauss J, Blackburn EH and Epel ES 2015 Determinants of telomere attrition over I year in healthy older women: stress and health behaviors matter. Molecular Psychiatry 20: 529-535. https://doi.org/l0.1038/mp.2014.70

Rafie N, Golpour Hamedani S, Barak F, Safavi SM and Miraghajani M 2017 Dietary patterns, food groups and telomere length: A systematic review of current studies. European Journal of Clinical Nutrition 7I: I5I-I58. https://doi.org /10.1038/ejcn.2016.149

Rahman MM, Callaghan CK, Kerskens CM, Chattarji S and O'Mara SM 2016 Early hippocampal volume loss as a marker of eventual memory deficits caused by repeated stress. Scientific Reports 6: I-I5. https://doi.org//0.1038/srep29/27

Ralph CR and Tilbrook AJ 2016 The usefulness of measuring glucocorticoids for assessing animal welfare. Journal of Animal Science 94: 457-470. https://doi.org//0.2527/jas.20I5-9645

Rolls ET 2013 What are emotional states, and why do we have them? Emotion Review 5: 24l-247. https://doi.org//0.1/77/ |7540739/34775 |4

Schutte NS and Malouff JM 2015 The association between depression and leukocyte telomere length: a meta-analysis. Depression and Anxiety 32: 229-238. https://doi.org/ |0.1002/da.2235 |

Seeker LA, Ilska JJ, Psifidi A, Wilbourn RV, Underwood SL, Fairlie J, Holland R, Froy H, Salvo-Chirnside E, Bagnall A, Whitelaw B, Coffey MP, Nussey DH and Banos G 2018 Bovine telomere dynamics and the association between telomere length and productive lifespan. Scientific Reports 8: 12748 Selye H 1956 The Stress of Life. McGraw-Hill: New York, NY, USA Sforza E, Celle S, Saint-Martin M, Barthélémy JC and Roche F 2016 Hippocampus volume and subjective sleepiness in older people with sleep-disordered breathing: A preliminary report. Journal of Sleep Research 25: 190-193. https://doi.org/I0.1 I I I/jsr.12367

Smith EL, Greenwood VJ, Goldsmith AR and Cuthill IC 2005 Effect of repetitive visual stimuli on behaviour and plasma corticosterone of European starlings. Animal Biology 55: 245-258. https://doi.org//0.1 I63/I570756054472827

Solomon Z, Tsur N, Levin Y, Uziel O, Lahav M and Ohry A 2017 The implications of war captivity and long-term psychopathology trajectories for telomere length. Psychoneuroendocrinology 81: I22-I28. https://doi.org/I0.1016 /j.psyneuen.2017.04.004

Spencer KA, Evans NP and Monaghan P 2009 Postnatal stress in birds: a novel model of glucocorticoid programming of the hypothalamic-pituitary-adrenal axis. Endocrinology 150: 19311934. https://doi.org//0.1210/en.2008-147I

Staffaroni AM, Tosun D, Lin J, Elahi FM, Casaletto KB, Wynn MJ, Patel N, Neuhaus J, Walters SM, Epel ES, Blackburn EH and Kramer JH 2018 Telomere attrition is associated with declines in medial temporal lobe volume and white matter microstructure in functionally independent older adults. Neurobiology of Aging 69: 68-75. https://doi.org//0.1016/ j.neurobiolaging.2018.04.021 
Steenstrup T, Hjelmborg JVB, Kark JD, Christensen K and Aviv A 2013 The telomere lengthening conundrum: Artifact or biology? Nucleic Acids Research 4I: I-7. https://doi.org/ 10.1093/nar/gkt370

Strandberg TE, Strandberg A, Saijonmaa O, Tilvis RS, Pitkälä KH and Fyhrquist F 2012 Association between alcohol consumption in healthy midlife and telomere length in older men. The Helsinki Businessmen Study. European Journal of Epidemiology 27: 8I5-822. https://doi.org//0.1007/s 10654-012-9728-0

Trochim WMK, Donnelly JP and Arora K 2015 Research Methods: The Essential Knowledge Base, Second Edition. Wadsworth Publishing: Belmont, CA, USA

UK Government 2012 The Animals (Scientific Procedures) Act 1986 Amendment Regulations 2012. https://www.legislation.gov.uk /ukdsi/2012/9780 I I 5303 I3

Walker M, Duggan G, Roulston N, Van Slack A and Mason G 2012 Negative affective states and their effects on morbidity, mortality and longevity. Animal Welfare 21: 497-509. https://doi.org/I 0.7I 20/09627286.21.4.497

Weich S, Patterson J, Shaw R and Stewart-Brown S 2009 Family relationships in childhood and common psychiatric disorders in later life: systematic review of prospective studies. British Journal of Psychiatry 194: 392-398. https://doi.org/ 10.1192/bjp.bp. 107.0425I5

Welfare Quality ${ }^{\circledR} 2009$ Welfare Quality ${ }^{\circledR}$ assessment protocol for poultry (broilers, laying hens). Welfare Quality ${ }^{\circledR}$ : Lelystad, The Netherlands.

Wilbourn RV, Moatt JP, Froy H, Walling CA, Nussey DH and Boonekamp JJ 2018 The relationship between telomere length and mortality risk in non-model vertebrate systems: A meta-analysis. Philosophical Transactions of the Royal Society B: Biological Sciences 373: 20160447. https://doi.org/l $0.1098 /$ rstb.2016.0447
Wild CP 2005 Complementing the genome with an 'exposome': The outstanding challenge of environmental exposure measurement in molecular epidemiology. Cancer Epidemiology Biomarkers and Prevention 14: 1847-/850. https://doi.org//0.II58/I0559965.EPI-05-0456

Wild CP 2012 The exposome: From concept to utility. International Journal of Epidemiology 4I: 24-32. https://doi.org/ 10.1093/ije/dyr236

Wise T, Radua J, Via E, Cardoner N, Abe O, Adams TM, Amico F, Cheng Y, Cole JH, de Azevedo Marques Périco C, Dickstein DP, Farrow TFD, Frodl T, Wagner G, Gotlib IH, Gruber O, Ham BJ, Job DE, Kempton MJ, Kim MJ, Koolschijn PCMP, Malhi GS, Mataix-Cols D, Mclntosh AM, Nugent AC, O'Brien JT, Pezzoli S, Phillips ML, Sachdev PS, Salvadore G, Selvaraj S, Stanfield AC, Thomas AJ, van Tol MJ, van der Wee NJA, Veltman DJ, Young AH, Fu CH, Cleare AJ and Arnone D 2017 Common and distinct patterns of grey-matter volume alteration in major depression and bipolar disorder: evidence from voxel-based meta-analysis. Molecular Psychiatry 22(I0): I455-|463. https://doi.org// 0.1038/mp.2016.72

Wojcicki JM, Medrano R, Lin J and Epel E 2018 Increased cellular aging by 3 years of age in Latino, preschool children who consume more sugar-sweetened beverages: A pilot study. Childhood Obesity 14(3): 149-157. https://doi.org/10.1089/chi.2017.0159

Woon FL, Sood S and Hedges DW 2010 Hippocampal volume deficits associated with exposure to psychological trauma and posttraumatic stress disorder in adults: A meta-analysis. Progress in Neuro-Psychopharmacology and Biological Psychiatry 34: I I8I-I | 88. https://doi.org/I0.1016/j.pnpbp.2010.06.016

Zimmerman ME, Ezzati A, Katz MJ, Lipton ML, Brickman AM, Sliwinski MJ and Lipton RB 2016 Perceived stress is differentially related to hippocampal subfield volumes among older adults. PLoS One II: e0I54530. https://doi.org//0.137I/journal.pone.0154530 